\title{
The Disaster Notification System Based SMS to Students at the School Vulnerable Flood Disaster using Single Board Computer of Raspberry Pi
}

\author{
Dedi Satria ${ }^{1}$, Saifuddin Muhammad Jalii ${ }^{2}$, Elin Yusibani ${ }^{3}$ \\ ${ }^{1}$ Computer Engineering Department, Universitas Serambi Mekkah, Banda Aceh, Indonesia, \\ dedisatria@serambimekkah.ac.id \\ ${ }^{2}$ Faculty of Engineering, Universitas Malikussaleh, Lhokseumawe, Indonesia, saifuddin@ unimal.ac.id \\ ${ }^{3}$ Electronic Engineering Department, Universitas Syiah Kuala, Banda Aceh, Indonesia, \\ e_yusibani@unsyiah.ac.id
}

\begin{abstract}
Schools as a community education center are one of the institutions that often receive floods. In particular, schools are included in areas that are prone to flooding. To anticipate school students being affected by the floods at school, a flood disaster notification system is needed aimed at the school to be alert or to avoid school. This paper aims to build a flood disaster notification system via SMS aimed at students and school teachers. Flood notification system is built using input components such as ultrasonic sensors and rain sensors, the processing component uses Raspberry Pi type Single Board Computer. and, the output component is a GSM modem. while software applications are built using the Apache web server application, PHP Engine and MySQL Database. This system development research resulted in an SMS-based school flood disaster notification system, with a web-based system administration application that is equipped with student and teacher data forms, flood reports and SMS recipient reports.
\end{abstract}

Key words : Flooding, Schools, Early Warning Systems, GSM, SMS, Information Systems, Single Board Computer, Raspberry Pi.

\section{INTRODUCTION}

Flood disasters nowadays often occur in various countries including Indonesia as a country located in the tropics where it has two seasons namely rainy season and dry season. Based on the two seasons that unbalanced natural conditions will give birth to conditions where both seasons will result in extreme conditions. Extreme conditions during the rainy season will result in natural disasters such as floods. Extreme conditions can occur due to weather factors or even due to human error factors in balancing nature such as forest destruction, garbage disposal into rivers and many other agi. From the list of mistakes it produces disasters that are detrimental to the community.
Flood disaster does not choose who will be the victim. Various areas such as housing, agricultural land and schools are some vital locations that have always been the target of global flood disasters.

Schools as a community education center are one of the institutions that often receive floods. In particular, schools are included in areas that are prone to flooding. Schools in general have students who basically do not all live in the same location as the school. There are some students outside the flood prone area studying at the school, and if there is a flood then the student does not know that there is a flood at the school. Based on these problems, we need a flood disaster notification system aimed at parents of students whose function is to provide information that the school is in a flood condition. With these notifications it will make it easier for parents and teachers to make the decision not to go to school and make independent learning.

Based on school cases in flood-prone areas, the government encourages many parties from the public and private sectors to be able to make a meaningful contribution to develop systems that can reduce victims of greater disasters such as flood early warning systems that are integrated with information systems that are easily accessible by the community [1].

Based on the government directives to researchers in various sectors, this paper aims to provide information on the work carried out in building a flood disaster notification system for schools in areas that are prone to flooding. And with the notification system can provide students with early information about the condition of the school when the flood occurred.

\section{LITERATURE SURVEY}

An integrated system consisting of input components consisting of sensors, processing components such as microcontrollers, communication system components and aimed at sending data from sensors wirelessly is called the Wireless Sensor Network [2]. The use of wireless sensor network systems has been widely implemented in a variety of industrial products, industrial manukatur, military, smart homes and in the early warning system equipment [3]. 
GSM (Global System for Mobile Communications) is one of the devices that can be implemented to communication devices on a wireless sensor network system. In addition there are also several other communication equipment such as Zigbee, Bluetooth and Wireless Local Area Network that can be used on wireless sensor network systems[4] [5].

However, communication systems using the GSM system (Global System for Mobile Communications) are far more efficient for use in the distribution of community-based information that is more common with mobile devices with SMS services. GSM services are chosen more easily because of the ease in getting the provider even in rural or outermost areas [6].

The application of embedded system applications in previous studies has been widely carried out. Especially in the application of flood information systems and disaster early warning systems. So therefore the authors conducted several surveys of the use of wireless sensor networks on flood early warning systems that had been built before. By tracing the research that has been done by previous researchers will generate new ideas for further development in applying the new system.

It is known that one of the main components in flood early warning systems is flood height detection. In some studies it is known that to determine the height of a flood using ultrasonic sensors as sensors to detect water levels [7]. And some of them use a combination of infrared sensor technology and ultrasonic sensors in measuring water level [8].

Whereas the processing component of some researchers uses a microcontroller system as a data processing component received by the sensor. The use of a microcontroller is used because it works in a mono tasking system so that data processing can be faster [9][10]. ATMEGA238 is a type of microcontroller that is often used on several prototypes of flood early warning systems used. The minimum system of the ATMEGA238 type that is easy to use is the minimum system produced under the trademark Arduino [1]. The Arduino drinking system board is an easy-to-use board for building prototypes of embedded system applications. And other advantages are often used in learning systems embedded in microcontroller based systems. The prototype of embedded system applications such as smart home products, smart agricultural media and various sectors of agricultural technology and disaster early warning devices such as fire have used Arduino as the basis for data processing media [11]. And also on the implementation of flood detection systems [12][13] [14][15]. Some use of communication systems on flood information system devices uses wireless sensor network models to send sensor data to their information system servers [16][17].

From several studies that have been done by previous researchers, we need a new innovation that can be developed is the use of Single Board Computer (SBC) devices such as Raspberry Pi in flood disaster notification systems in disaster prone school applications.

\section{METHOD}

The research method carried out on developing a flood disaster notification system for students for disaster-prone schools is to use the Software Development Life Cycle (SDLC) method which is applied to the hardware and software development process. The main stages of developing the system are the stages of the overall system description in the form of system analysis, the second stage of the design of the flood detector system and the SMS gateway-based notification system.

\subsection{Analisa Sistem}

The first stage is a system analysis that will explain the description of the working system flow starting from the sensor to the students. In Figure 1 it can be explained that beginning with the admin or system operator entering student and teacher data into the disaster notification system database. Second, the sensor measures the water level and detects the state of the rain. Third, the disaster notification system sends flood disaster information at school to students and teachers via SMS.

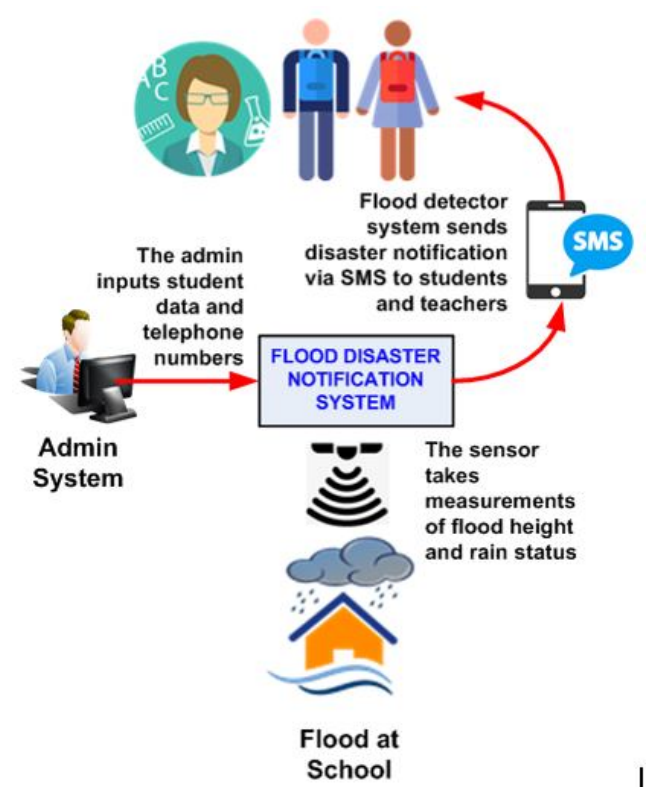

Figure 1: System Analysis

\subsection{System Design}

The second stage is to design a flood disaster notification system in the form of hardware design and software design. For hardware design as shown in Figure 2, it can be explained that the hardware system has an input component consisting of an ultrasonic sensor as a water level detector, a rain sensor as a rain status detector. Furthermore, the sensor components are connected to a Raspberry Pi single board computer (SBC) as the data processor. Raspberry Pi data processing using server applications such as Apache Web Server, PHP Engine and MySQL DBMS and followed by Gammu which is the SMS Gateway application. and, finally, the GSM USB modem component that is connected to the Raspberry Pi. 


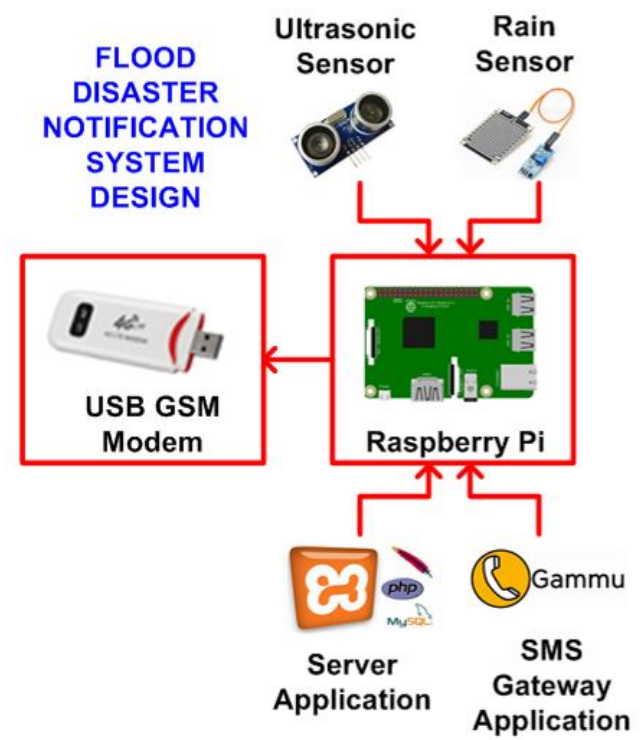

Figure 2:Flood Disaster Notification System Design

Furthermore, in Figure 2 there is also a flood information system block. In the block, there are several supporting system components, namely the component of the GSM modem receiver type Wavecom M1306B. The GSM modem functions as a data receiver modem. Data received by the modem will be processed on a Personal Computer that functions as a flood information system server with supporting application components such as the Gammu application functioning as an SMS Gateway application, Apache web server as a web server, PHP Engine and MySQL as a database management system and the Google Maps API as an API geospatial.

The software design is represented by the context diagram design of the flood disaster notification system. The context diagram as shown in Figure 3 can be explained that there are two users namely the system operator whose task is to input student, teacher and telephone data and store them in the flood disaster notification system database. While users of students and teachers only receive notifications in the form of information on floods that occur at school via SMS sent from the flood disaster notification system.

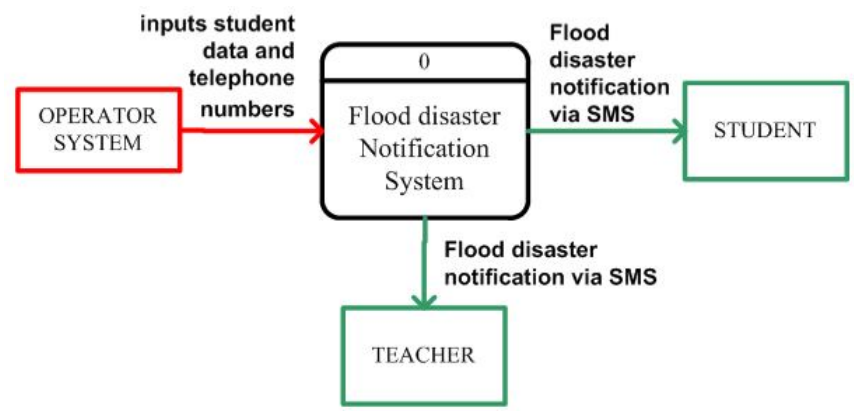

Figure 3: Context Diagram of Flood Disaster Notification System Design

\section{RESULT}

Based on the analysis and design phases that have been built, the disaster notification system for school students has produced a prototype of a flood detector system that is integrated with a Raspberry Pi-based information system that can send information on flood disasters that occur in schools via SMS. The results of the prototype that have been built can be seen in Figure 4 and can be explained that the flood disaster notification system consists of paralon pipes that function as a medium for measuring water levels. Paralon pipe used in this prototype has a height of $80 \mathrm{~cm}$. Notification system is placed on the side of the pipe. The location of the main components placed on the side of the pipe is only aimed at the prototype. Whereas in the actual implementation required a special box separate from the pipe paralon in a safe condition from flooding.

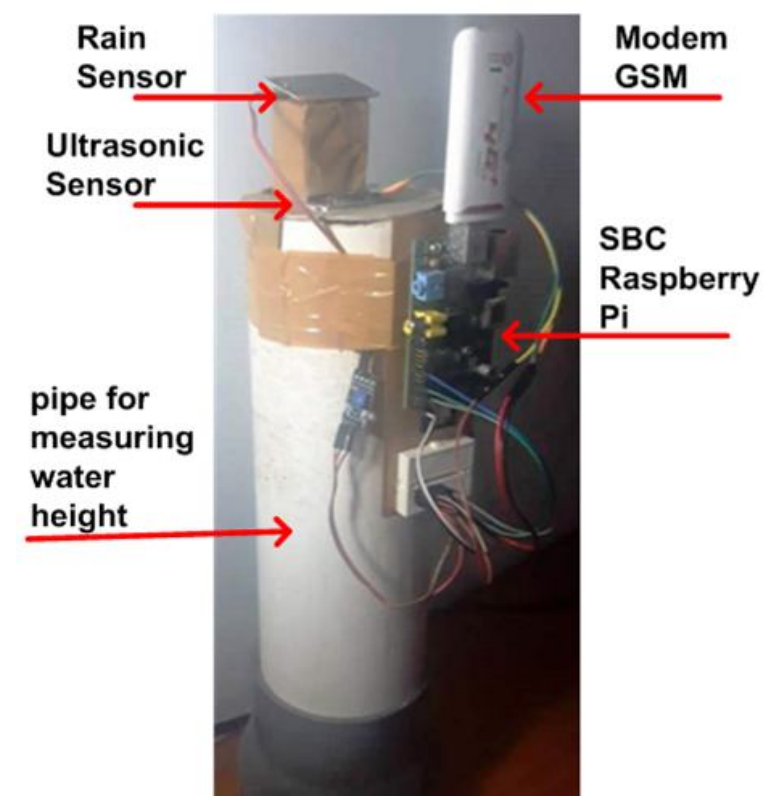

Figure 4: Flood Disaster Notification System

Ultrasonic sensor component as an input component that has been installed on the top side of the pipe paralon. Followed by a rain sensor component which is placed on the top side of the ultrasonic sensor. Figure 4 also shows that a GSM USB modem is installed on a USB port on the Raspberry Pi Single Board Computer System.

While flood disaster notification system applications that are built using server applications such as Apache Web Server, PHP Engine and MySQL DBMS can be seen in Figure 5. The application is built based on a web interface that is equipped with several forms including student and teacher data input forms. The data entered is the user type, name and telephone number as shown in Figure 5. 


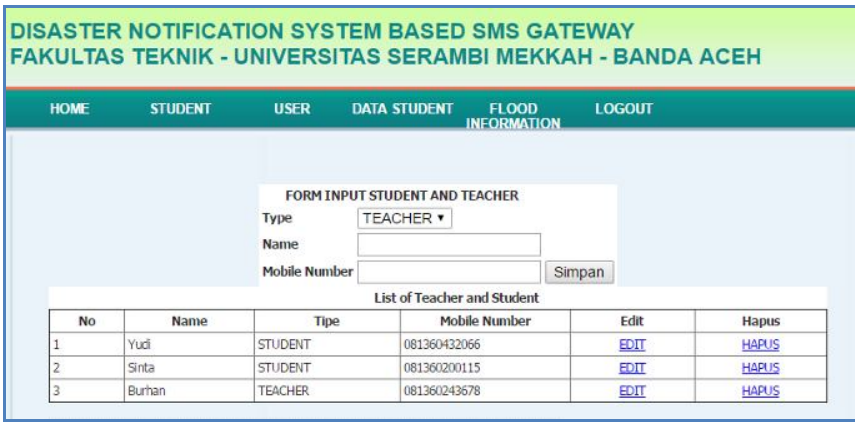

Figure 5:Student and Teacher Input Forms

The next interface as shown in Figure 6 is a flood information report that has been stored by a database with a column containing data on the date, time, height of the flood, the status of the rain at that time and a menu link report receiving SMS messages that received flood information at that time.

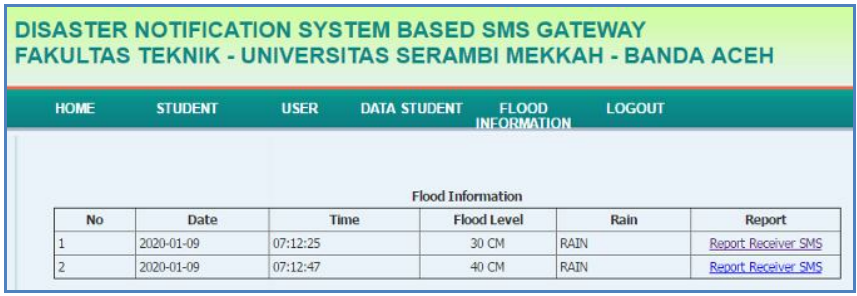

Figure 6: Report of Flood Information

The third interface is the report list of SMS recipients who have received flood information notification sent at school from the flood notification system. The data displayed on the report are the name of the student or teacher, telephone number and SMS status as shown in Figure 7.

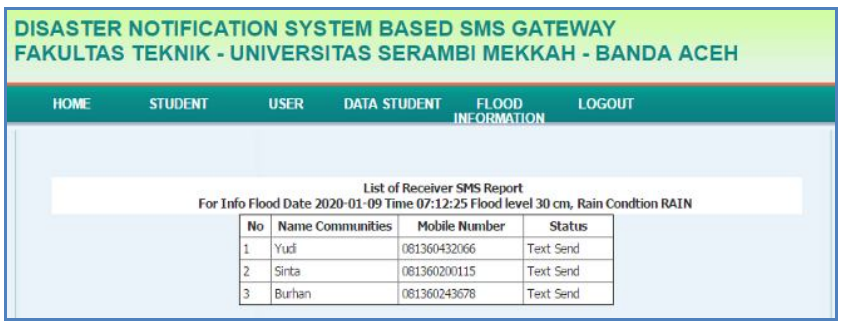

Figure 7: Flood notification SMS recipient report data

While the form of SMS received by students can be seen in Figure 8. The format of SMS received is "To Yudi Students, informed that the school is currently in a flood condition and the learning process is closed (By System)".

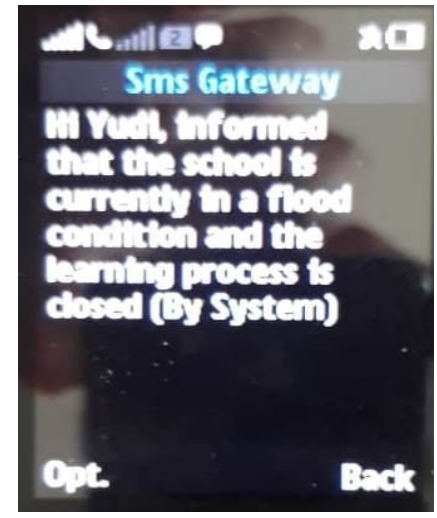

Figure 8: SMS text received by student

While the form of SMS received by the teacher can be seen in Figure 9. The format of the SMS received was "To the Burhan Teacher, it was informed that the school was currently in a flood condition and the learning process was closed. For information about further information from the school management system, contact the school leader (By System).

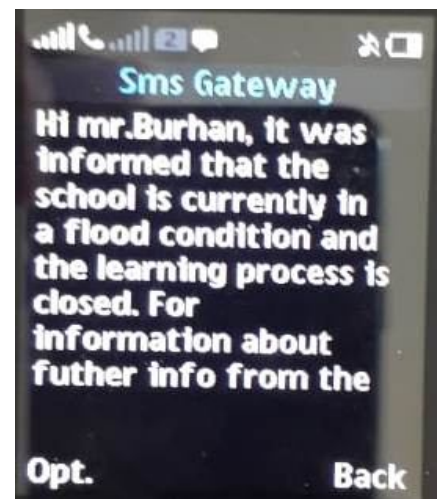

Figure 9: SMS text received by teacher

\section{CONCLUSION}

From the analysis, design and results of making a prototype of a flood notification system to students and teachers, it can be concluded that the flood notification system via SMS gateway using the Raspberry Pi Single Board Computer has run in accordance with the system analysis that was designed. Furthermore, the system was tested using components that have been described in hardware design such as using input components, namely ultrasonic sensors and rain sensors, using Raspberry Single Board Computer based processing components, and output components, namely GSM USB modems. Likewise in testing the web-based flood disaster notification application software has been built using server applications such as Apache Web Server, PHP Engine and MySQL Database. The system built is a prototype that has been tested on a laboratory scale. So for the perfection of the next system, further research is needed by utilizing sensors, processing media and integration between other applications. 


\section{ACKNOWLEDGEMENT}

The Ministry of Research and Higher Education (Ristekdikti) of the Republic of Indonesia through the Higher Education Collaboration Research Scheme (PKPT) with contract number 119 / SP2H / LT / DRPM / 2019. This research was conducted jointly by a research team from Serambi Mecca University and a team from Syiah Kuala University as a Research Partner Team.

\section{REFERENCES}

[1] D. Satria, S. Yana, E. Yusibani, S. Syahreza, and Z. Maizi, "Implementation of GSM communication on flood monitoring systems based on multiple locations visualization," Int. J. Recent Technol. Eng., vol. 8, no. 3, pp. 8215-8219, 2019.

https://doi.org/10.35940/ijrte.C6704.098319

[2] R. J. M. Mercado, "Design of wireless sensor networks using embedded Programmable System-on-Chip (PSoC) as applied to community-based flood early warning systems (CBFEWS)," in 2016 International Conference on Advances in Electrical, Electronic and Systems Engineering (ICAEES), 2016, pp. 214-223.

[3] B. N. Silva, M. Khan, and K. Han, "Towards sustainable smart cities: A review of trends, architectures, components, and open challenges in smart cities," Sustain. Cities Soc., vol. 38, no. January, pp. 697-713, 2018. https://doi.org/10.1016/j.scs.2018.01.053

[4] D. Satria, Zulfan, Munawir, and T. Hidayat, "Implementation of wireless sensor network (WSN) on garbage transport warning information system using GSM module," in Journal of Physics: Conference Series, 2019, vol. 1175, no. 1.

[5] S. Meliala, Saifuddin, and Rosdiana, "Drying design model for dried-anchovy using solar collector and solar cell panel position control," Int. J. Recent Technol. Eng., vol. 7, no. 6, pp. 1430-1436, 2019.

[6] A. J. Falade, O. Mohammed, A. Y. Abdulrahman, and L. Kadir, "Tower sharing and the associated constraints in multi-operator GSM base transceiver station," Int. J. Wirel. Mob. Comput., vol. 11, no. 3, p. 198, 2016.

https://doi.org/10.1504/IJWMC.2016.10002155

[7]

W. Indrasari, B. H. Iswanto, and M. Andayani, "Early Warning System of Flood Disaster Based on Ultrasonic Sensors and Wireless Technology," IOP Conf. Ser. Mater. Sci. Eng., vol. 335, no. 1, 2018.

[8] M. Mousa, X. Zhang, and C. Claudel, "Flash Flood Detection in Urban Cities Using Ultrasonic and Infrared Sensors," IEEE Sens. J., vol. 16, no. 19, pp. 7204-7216, 2016.

https://doi.org/10.1109/JSEN.2016.2592359

[9] S. M. Jalil, L. Abdullah, I. Ahmad, and H. Abdullah, "The effect of surface texturing on GaAs solar cell using TCAD tools," in 2008 IEEE International Conference on Semiconductor Electronics, 2008, pp. 280-283.

[10] S. M. Jalil, F. Abdurrahman, S. Meliala, and Rosdiana, "Design of maximum power point tracking for solar collector drying system: An experimental study," Int. J. Power Electron. Drive Syst., vol. 9, no. 4, pp. 1799-1803, 2018.

[11] S. S. Dewi, D. Satria, D. Mulyati, D. Sugiyanto, and E. Yusibani, "Implementation of Internet of Thing on Fire Home Information Systems for Multi Room applications Implementation of Internet of Thing on Fire Home Information Systems for Multi Room applications," J. Phys. Conf. Ser. 1232, 2019.

[12] D. Satria, S. Yana, E. Yusibani, S. Syahreza, and Zulfan, "Implementation of the SMS Gateway in the Flood Early Warning Information System for Village Warning and Community Information," Int. J. Eng. Adv. Technol., vol. 8, no. 6, pp. 4005-4009, 2019. https://doi.org/10.35940/ijeat.F9287.088619

[13] S. Azid, B. Sharma, K. Raghuwaiya, A. Chand, S. Prasad, and A Jacquier, "SMS Based Flood Monitoring and Early Warning Systems," ARPN J. Eng. Appl. Sci., vol. 10, no. Vol. 10, No.15, pp. 6387-6391, 2015.

[14] J. G. Natividad and J. M. Mendez, "Flood Monitoring and Early Warning System Using Ultrasonic Sensor," IOP Conf. Ser. Mater. Sci. Eng., vol. 325, no. 1, 2018.

[15] D. Satria, S. Yana, E. Yusibani, and S. Syahreza, "Visualization System for Water Levels and Environmental Conditions in the Flood Monitoring Information System," Int. J. Innov. Technol. Explor. Eng., vol. 8, no. 11, pp. 2904-2907, 2019.

[16] V. Seal, a Raha, S. Maity, and S. Mitra, "A Simple Flood Forecasting Scheme Using Wireless Sensor Networks," Int. J. Ad hoc, Sens. Ubiquitous Comput., vol. 3, no. 1, pp. 45-60, 2012.

https://doi.org/10.5121/ijasuc.2012.3105

[17] M. M. Kamal, N. A. Z. M. Noar, and A. M. Sabri, "Development of detection and flood monitoring via blynk apps," Indones. J. Electr. Eng. Comput. Sci., vol. 10, no. 1, pp. 361-370, 2018.

https://doi.org/10.11591/ijeecs.v10.i1.pp361-370 